
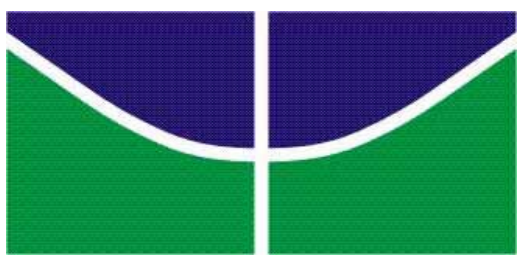

Universidade de Brasília

Centro de Excelência em Turismo

\title{
AGROTURISMO: IMPLANTAÇÃO E DESENVOLVIMENTO DE UMA MODALIDADE DE TURISMO NO ESPAÇO RURAL
}

\author{
Tharso Padilha Nogueira
}

Mariana Aldrigui Carvalho

Monografia apresentada ao Centro de Excelência em Tursimo da Universidade de Brasília como requisito parcial para obtenção do certificado de Especialista em Gestão da Hospitalidade.

Brasília, DF, novembro de 2003. 
UNIVERSIDADE DE BRASÍLIA

Centro de Excelência em Turismo

Curso de Especialização em Gestão da Hospitalidade

\title{
AGROTURISMO: IMPLANTAÇÃO E DESENVOLVIMENTO DE UMA MODALIDADE DE TURISMO NO ESPAÇO RURAL
}

Tharso Padilha Nogueira

\author{
Banca Examinadora \\ Mariana Aldrigui Carvalho, Mestre \\ Orientadora \\ Membro da Banca Examinadora
}

Brasília, DF, 26 de novembro de 2003. 
THARSO PADILHA NOGUEIRA

AGROTURISMO: IMPLANTAÇÃO E DESENVOLVIMENTO DE UMA MODALIDAE DE TURISMO NO ESPAÇO RURAL

Comissão Avaliadora

Mariana Aldrigui Carvalho

Prof. Membro da Comissão

Prof. Membro da Comissão

Brasília, 26 de novembro de 2003. 
Dedico este trabalho

A Deus, pelo dom da vida; $e$

Aos meus pais, Dorismar e Lúcia, pelo exemplo. 


\section{Agradecimentos,}

Desejo expressar meus sinceros agradecimentos, de modo especial à minha orientadora, professora Mariana, pelo empenho e confiança no êxito deste trabalho.

Aos meus colegas de turma, pelo incentivo mútuo dentro e fora de classe.

Aos meus amigos, João Batista Júnior e Washington Mariano. 
“... não é por outro motivo que esse segmento se põe a desfazer a feição um tanto elitista do turismo, isolando-se da mesmice habitual. Aquela situação ridícula do antigo 'hotel-fazenda', onde se achava o hotel e se ficava procurando a fazenda. Dois cavalinhos famintos, meia dúzia de galinhas sofridas e a enfadonha roda de carroça, para enganar o visitante outrora desavisado. O turista de hoje cobra autenticidade e busca na verdadeira prática agropastoril sua melhor participação. Não se trata mais de um mero espectador, ele já se inclui no tema."

Renato Bravo 


\section{RESUMO}

Este trabalho apresenta uma evolução histórica do turismo no espaço rural, introduzindo o leitor ao início das práticas de hospitalidade no decorrer da história da humanidade. Com objetivo de diferenciar o Agroturismo das demais modalidades de Turismo no Espaço Rural, traz definições de diversos autores e enfatiza a atividade do Agroturismo como sendo a única que realmente interage com o turista. Identifica também a potencialidade das regiões brasileiras com a implantação de empreendimentos agroturísticos em propriedades tipicamente rurais e as dificuldades encontradas pelos produtores para adaptação da nova atividade econômica na propriedade. Além de mostrar as principais entidades públicas envolvidas com o negócio agroturístico, o trabalho expõe algumas ações dessas entidades que vem contribuindo para o desenvolvimento do Agroturismo no Brasil e ajudando àquelas propriedades com o empreendimento já implantado a obter os resultados que motivaram ao seu ingresso: gerar renda e emprego, outrora escassos por fatores como a crescente concorrência com poderosos aglomerados agro-industriais.

Palavras-chave: Agroturismo, Turismo no Espaço Rural, SEBRAE 


\begin{abstract}
This work presents a historical evolution of the tourism in the agricultural space, introducing the reader to the beginning of the practical ones of hospitality in elapsing of the history of the humanity. With objective to differentiate the Agroturismo of the too much modalities of Tourism in the Agricultural Space, it brings definitions of diverse authors and it emphasizes the activity of the Agroturismo as being the only one that it really interacts with the tourist. It also identifies to the potentiality of the Brazilian regions with the implantation of agroturísticos enterprises in typically agricultural properties and the difficulties found for the producers for adaptation of the new economic activity in the property. Besides showing the main involved public entities with the agroturístico business, the work displays some actions of these entities that come contributing for the development of the Agroturismo in Brazil and helping to those properties with the enterprise already implanted to get the results that had motivated to its ingression: to generate income and job, long ago scarce for factors as the increasing competition with powerful agro-industrial accumulations.
\end{abstract}

Key-words: Agroturismo, Tourism in the Agricultural Space, SEBRAE 


\section{SUMÁRIO}

\section{PÁGINA}

Considerações Iniciais............................................................................. 1

Introdução.................................................................................... 1

Capítulo I. Antecedentes Históricos do Agroturismo................................... 2

I.I. O problema e sua importância........................................................ 5

I.II. Metodologia................................................................................. 7

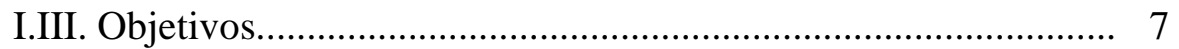

Capítulo II. O Agroturismo em Documentos Teóricos................................ 8

Capítulo III. Agroturismo: em busca de uma definição............................. 13

III.I. O Agroturismo Técnico.............................................................. 15

Capítulo IV. O Potencial do Agroturismo no Brasil................................... 17

Capítulo V. Experiências Bem Sucedidas do Agroturismo........................ 19

V.I. Venda Nova do Imigrante - ES.................................................. 19

V.II. O Distrito Federal.................................................................... 21

Capítulo VI. As Entidades Governamentais e suas Ações......................... 23

VI.I. O SEBRAE .......................................................................... 23

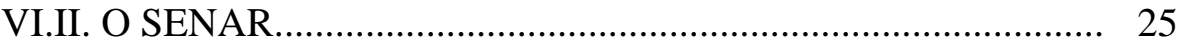

VI.III. O Ministério do Turismo.......................................................... 26

VI.IV. O Ministério da Agricultura e do Abastecimento.................... 28

Considerações Finais............................................................................. 28

Referências Bibliográficas....................................................................... 31 


\section{Considerações Iniciais}

O principal interesse em tratar desse assunto, é de ordem pessoal. Uma vez que o trabalho visa também dar continuidade a um projeto apresentado na graduação do curso de Economia e que tinha como abordagem o Agrobusiness, como alavanca do crescimento econômico do País.

Por considerar o Agroturismo como uma atividade que, brevemente irá compor o quadro do complexo do agronegócio, é de relevante importância os estudos do tema em um mercado de turismo no espaço rural, que é bastante promissor, principalmente quando considera que o crescimento econômico, o aumento do poder aquisitivo e as pressões diárias sofridas pelo homem urbano são forças estimuladoras desse mercado, e no ambiente rural que a população urbana tem buscado equilíbrio.

\section{Introdução}

A área rural não se restringe mais àquelas atividades relacionadas à agropecuária e agroindústria. Nas últimas décadas, o meio rural vem ganhando novas funções agrícolas ou não agrícolas e oferecendo novas oportunidades de trabalho e renda para as famílias. Agora, a agropecuária moderna e a agricultura de subsistência dividem espaço com um conjunto de atividades ligadas ao lazer, prestação de serviços e até à indústria, reduzindo, cada vez mais, os limites entre o meio rural e o urbano e abrindo amplo espaço para as atividades de recreação, de lazer e de turismo.

Como já é de conhecimento geral, o meio urbano é a grande área emissora dos turistas que buscam o meio rural e estes lugares ditos "naturais", atendendo aos apelos da mídia que procura constantemente veicular a "ideologia do retorno a natureza", fundamentada no 
discurso da vida citadina como massacrante e estressante, cujo cotidiano tende a distanciar as pessoas da vida saudável, de modo que elas devam buscar nas viagens agroturísticas e/ou ecoturísticas o descanso e a paz há muito perdidos nos grandes centros.

Neste trabalho iremos dar ênfase ao Agroturismo, um segmento que recentemente vem sendo explorado em todo mundo e que é uma das submodalidades do Turismo no Espaço Rural. Segundo Portuguez (1999 p. 82), “o agroturismo em suas várias versões começou a se projetar em todo o mundo a partir da década de 60, embora algumas experiências bemsucedidas tenham ocorrido em períodos anteriores”. Ainda de acordo com este autor, o agroturismo pode ser entendido como "a modalidade de turismo em espaço rural praticada dentro das propriedades, de modo que o turista e/ou excursionista entra, mesmo que por curto espaço de tempo, em contato com a atmosfera da vida na fazenda, integrando-se de alguma forma aos hábitos locais.” O trabalho visa mostrar, em capítulos oportunos, o surgimento deste negócio e as experiências do Agroturismo no Brasil além de diferenciá-lo de outras modalidades do Turismo no Espaço Rural.

\section{Capítulo I. Antecedentes Históricos do Agroturismo}

A palavra Turismo não apareceu na língua inglesa senão no começo do século XIX. A palavra também estava mais associada à idéia de uma viagem ou turnê teatral do que à idéia de um indivíduo "viajando somente por prazer, que é a acepção em uso atualmente”. O Turismo pode ser definido como a ciência, a arte e a atividade comercial especializados em atrair e transportar visitantes, acomodá-los e atender, com cortesia, as suas necessidades e desejos. (Walker, 2002: p.139)

As primeiras referências à hospitalidade remontam à Grécia e Roma antigas, quando o incremento do comércio e das viagens fez o aparecimento de alguma forma de acomodação para passar a noite se tornasse uma necessidade. Em seguida observamos os antigos persas que criaram uma combinação de estábulos e pousadas chamadas de Khans, com o propósito de 
atender às caravanas de viagem. E somente na Idade Média, mais precisamente na Europa, as práticas da hospitalidade começavam a se aperfeiçoar. Com a rápida expansão do comércio um dos efeitos mais importantes foi o crescimento das cidades. Huberman (1973: p.35) diferencia o desenvolvimento:

\begin{abstract}
"Sem dúvida, havia certo tipo de cidades antes desse aumento no comércio, os centros militares e judiciais do país, onde se realizavam os julgamentos e onde havia bastante movimento. Eram realmente cidades rurais, sem privilégios especiais ou governo que as diferenciasse. Mas as novas cidades que se desenvolveram com a intensificação do comércio, ou as antigas cidades que adotaram uma vida nova sob tal estímulo, adquiriram um aspecto diferente.”
\end{abstract}

Com a transformação das cidades, as viagens se intensificaram e as tavernas tornaram-se centros sociais e políticos. Nas zonas rurais, uma única estalagem servia a todos os viajantes, muito embora marcantes diferenças pudessem ser observadas no tratamento dispensado aos diferentes hóspedes: os viajantes com posses eram servidos nos salões de jantar ou em seus quartos; os mais pobres eram invariavelmente obrigados a comer com o senhorio e sua família na cozinha, tendo direito somente ao prato da casa a preço de custo.

Muitos dos valores da hospitalidade medieval ajustam-se aos dias de hoje, tais como o serviço amigável, a atmosfera amena e a abundância de comida. Comparados à nossa época, os padrões sanitários eram pobres e as acomodações primitivas.

Desta forma, num processo cada vez mais irreversível, a idéia de se organizar viagens para fins comerciais, bélicos ou não, já era uma realidade na sociedade européia. Em 1552 (segunda metade do século XVI), foi elaborado na França, por Charles Estiene, o primeiro guia de estradas, com roteiro e descrição de vários espaços atrativos para os primeiros hábitos de viagem. Quase 60 anos depois, no início do século XVII, por volta do ano de 1612, apareceram outras publicações direcionadas para sensibilizar e orientar aqueles que tinham interesse por viagens. Dentre elas podemos citar o primeiro manual de guia turístico, denominado Of Travel (das viagens), escrito por Francis Bacon, com roteiros e indicações para viajantes de todas as modalidades e tipos. Essas inovações associadas à nova estruturação 
urbana provocaram mais facilidades para os deslocamentos de diversas pessoas gerando mais contatos entre os povos e uma maior troca de informações.

Fazendo uma regressão na história da humanidade, podemos observar que a hospitalidade no meio rural, já se prosperava pelo fato do não desenvolvimento das cidades.

Entretanto, o grande divisor de águas na história da humanidade, foi a Revolução Industrial ocorrida, aproximadamente, por volta de 1760 (segunda metade do século XVIII) na Inglaterra, quando houve verdadeiras e definitivas transformações na qualidade de vida e, acima de tudo, nos meios de comunicação e transportes trocando-se a carruagem pela locomotiva, tornando mais rápidas as viagens e oferecendo mais tranqüilidade, conforto e proteção para os viajantes.

Do ponto de vista organizacional e estrutural, no século XX a indústria do turismo passa a ter importância. Em 1925, realizou-se o Primeiro Congresso Internacional de Associações Oficiais de Propaganda de Turismo. Dois anos depois, aconteceu o Congresso Internacional de Organismos Oficiais de Turismo, no qual foi criada a primeira organização voltada, única e exclusivamente, para esta atividade denominada União Internacional de Organizações Oficiais para a Propaganda Turística. E mais adiante o surgimento da OMT - Organização Mundial do Turismo - e outras entidades que tem como propósito estudar, organizar e fomentar esta atividade. Com o avanço dos estudos nessa nova Ciência surgem vários conceitos de Turismo, modalidades e formas de exploração do mesmo, dentre eles o Turismo no Espaço Rural.

As grandes transformações político-econômicas e técnico-científicas, acompanhadas da explosão econômica global, repercutiram na definição de novos valores, no aparecimento de novas necessidades, na alteração dos hábitos de consumo e na adoção das novas medidas. A economia pós-industrial vem sendo caracterizada pela predominância das atividades de serviços, além da automação nas indústrias, da informatização dos processos burocráticos e da busca das belezas naturais. 


\section{I.I. O problema e sua importância}

Do ponto de vista do meio rural, observa-se que os donos de pequenas e médias propriedades vêm enfrentando, uma crescente descapitalização provocada por diversos fatores econômicos, agravados pela concorrência dos grandes e poderosos conglomerados agroindustrias, que impõem o preço de mercado, o que inviabiliza o pequeno produtor.

O Agroturismo como um segmento voltado para atividades relacionadas com o mundo agrícola é um dos que mais cresce no País, e tem possibilitado uma mudança no perfil do emprego no campo. Embora o seu crescimento seja de certa forma espontâneo com pouco ou nenhum planejamento na maioria das regiões brasileiras onde ocorre, seu papel vem se tornando cada dia mais significativo, representando uma alternativa real de renda para populações rurais. Além dessa forma de alternativa de renda, é um negócio que permite aos proprietários rurais manterem suas propriedades produtivas, verticalizando a produção e consequentemente gerando o emprego para população local.

Outro aspecto dessa atividade é o despertar da consciência ecológica, ao transformar os produtores em agentes conservadores da natureza, sobretudo à medida que eles percebem o turismo como fonte de renda. Corresponde ainda a uma forma de lazer saudável, na qual valores culturais e regionais são resgatados e valorizados. Trata-se de um negócio propício para o Brasil, com grande extensão territorial, diversidade cultural e um número considerável de sítios, chácaras e fazendas, tendo em vista que impulsiona a economia agrícola e estimula o desenvolvimento de regiões.

Podemos sintetizar como objetivos básicos do turismo no espaço rural

- Promover a integração entre o campo e a cidade;

- Melhorar a qualidade de vida da população urbana e rural;

- Viabilizar uma nova fonte de renda ao produtor rural;

- Promover a verticalização da produção;

- Resgatar e valorizar a cultura local e regional; e 
- Promover a participação da comunidade local.

Sob o aspecto mercadológico, o turismo no espaço rural possibilita o contato direto entre o produtor e consumidor final, com a venda de hospedagem/serviços, de seus produtos in natura ou beneficiados e até mesmo o artesanato local. Esse contato direto resulta em preços e qualidade melhores para os dois lados, pela ausência de intermediários, transporte, armazenamento, etc.

Os benefícios trazidos pela implantação do Agroturismo nas propriedades agrícolas ofuscam os proprietários despreparados para enfrentar uma nova realidade mercadológica e um tipo de consumidor mais exigente e atento aos seus direitos. O produtor local muitas das vezes desconhece as etapas de organização empreendedora e pula etapas importantes como um Cadastro Nacional de Pessoas Jurídicas, no Ministério da Fazenda, um alvará de funcionamento, entre outras. Diante de tantos procedimentos, o importante é buscar apoio em órgãos públicos locais, que tem grande interesse em apoiar iniciativas no segmento turístico.

Com a preocupação do proprietário em montar seu negócio de Agroturismo, buscando apoio de entidades como o SEBRAE ou até mesmo a Prefeitura local, este produtor evitará problemas como a má qualidade do atendimento, das vias de acesso, da sinalização e da infraestrutura do local, que são os problemas já identificados nos empreendimentos agroturísticos implantados sem nenhum planejamento prévio.

Seria interessante que se adotasse esses procedimentos para tornar a propriedade agrícola mais atraente para seus visitantes, e assim suplementar a renda do produtor rural e que a principal atividade econômica do local, ou seja, a exploração agrária não seja esquecida, afinal o empreendimento agroturístico é totalmente dependente dessa atividade. 


\section{I.II. Metodologia}

A metodologia aplicada nesta monografia será uma revisão bibliográfica, com ênfase em elementos da história do Turismo e da Hospitalidade, e elementos econômicos, como produção agrícola e geração de renda e emprego.

Este método de pesquisa se deve por falta de recurso humanos e pouco tempo disponível para a realização de pesquisas de campo e aplicação de questionários, que resultariam em um trabalho mais completo para a identificação de pontos fortes e fracos da atividade do agroturismo implantada nas propriedades rurais pioneiras no Brasil.

\section{I.III. Objetivos}

A importância do estudo se deve à crescente transformação do Turismo no Espaço Rural, como atividade econômica de grande expressão no Brasil e no mundo, à medida que a disseminação de informações, a redução de custos de transporte, os investimentos em infraestrutura e o aumento da renda mundial têm propiciado um crescimento explosivo da demanda e da oferta de serviços turísticos.

O trabalho tem como objetivo principal:

- Identificar as experiências nacionais pioneiras em Agroturismo e os principais órgãos de apoio a generalização das práticas desta atividade no espaço rural brasileiro. 


\section{Capítulo II. O Agroturismo em Documentos Teóricos}

Para mostrar como as propriedades tipicamente agrícolas têm passado por constantes transformações, até a chegada de um novo modelo de obtenção de renda e geração de empregos Graziano (1996), apresenta em sua obra, logo nos primeiros capítulos, o processo histórico de passagem da agricultura brasileira do chamado “complexo rural” para uma dinâmica comandada pelos “complexos agro-industriais” - CAIs: a substituição da economia natural por atividades agrícolas integradas à indústria, a intensificação da divisão do trabalho e das trocas intersetoriais, a especialização da produção agrícola e a substituição das exportações pelo consumo produtivo interno como elemento central da alocação dos recursos produtivos no setor agropecuário. O autor desenvolve a idéia “de que havia uma nova dinâmica em gestação por trás daquilo que se convencionou chamar de "modernização conservadora” da nossa economia”.

Mais adiante, o autor mostra como por trás dos vários complexos havia uma administração do Estado através das políticas agrícolas e não-agrícolas, as quais eram diferentes das políticas de épocas anteriores porque expressavam interesses de outros grupos econômicos. Neste ponto, o autor se baseia na "balconização" do Estado e a sua conseqüente perda de poder regulador setorial em função do crescente fracionamento dos interesses do que se poderia chamar de rural, agrário ou ainda mais restritamente, de agrícola.

Nos capítulos finais de sua obra, o autor analisa as políticas agrícola e agrárias dos anos 80, e como a ação do Estado foi decisiva para separar os que ganharam dos que perderam através de “combinações brutais” de arrochos salariais e políticas cambiais. Discute ainda, a relação entre distribuição de renda, preço dos alimentos e padrão de desenvolvimento agrícola, argumentando que "o problema da fome no Brasil dos anos 90 está fundamentalmente relacionado à questão do baixo poder aquisitivo da classe trabalhadora. Em anexo, o autor apresenta notas para a formulação de uma abordagem alternativa para a análise da formação dos preços agrícolas no país. As políticas agrícolas precisam incorporar a questão do emprego 
rural e da sobrevivência da pequena produção familiar, não só pela órbita produtiva, mas também pelos seus aspectos sociais.

O autor conclui, com ênfase, que se persistir o enfoque meramente produtivista nas políticas agrícolas, os pequenos produtores tendem a ficar cada vez mais a margem da órbita produtiva.

Com relação às mudanças comportamentais dos produtores rurais para se adequarem à nova realidade econômica, Mendonça (2003) esclarece o ocorrido na década de 1980, com o Brasil vivenciando um momento peculiar caracterizado pela introdução dessa modalidade de turismo como alternativa de exploração econômica e resgate da valorização do meio rural. Acreditou-se que a atividade de turismo, quando bem planejada, seria uma estratégia de suplementação ou complementação dentro da propriedade rural, permitindo a estabilidade da organização e a integração das atividades tradicionais. Futuramente o turismo no espaço rural poderia ser o alicerce para o desenvolvimento rural. No entanto, é importante ressaltar que o setor de turismo e o setor rural apresentam características diferentes. No turismo são prestados serviços e no setor rural são produzidos, em sua maioria, essencialmente bens de primeira necessidade. No que diz respeito à gestão dos mesmos, cada qual demanda uma forma de gerir o setor, de acordo com suas características.

O setor de turismo é caracterizado por não ter uma função da produção formal, por ser fragmentado e multisetorial e não ter uma estrutura comum às outras indústrias que o represente. É constituído por agentes dos setores público, privado e, ainda, da comunidade local e seu produto é intangível (Corner, 2001 e Lickorish e Jenkins, 2000). Essas características tornam sua gestão mais complexa, exigindo maior profissionalização e formalização dos procedimentos gerenciais, além de demandar uma integração das partes envolvidas na atividade.

No caso do setor rural, este apresenta aspectos peculiares que o individualiza como seu processo de produção que o distingue da organização da produção do setor de turismo e do sistema de vida urbano. Entre os aspectos peculiares estão a dependência da produção 
primária, condições climáticas e biológicas que o homem não pode controlar resultando em incertezas quanto ao volume e qualidade da produção. Estas incertezas, por sua vez, geram, na área de comercialização, conseqüências sérias que podem representar para o produtor, grandes e reais prejuízos. Além desses aspectos existem também, os problemas freqüentes de baixos preços recebidos e a sua extrema variabilidade, custos altos de insumos e, consequentemente, de produção (Aires e Rentero, 1992). Em relação à produção, em geral, é definida com base nos costumes familiares e regionais, o produto é tangível e os procedimentos gerenciais são utilizados informalmente.

O produtor culturalmente conduz o negócio isoladamente e é resistente a inovações, quando estas estão fora de seu domínio de conhecimento. Lucena (1992) comenta a este respeito que, geralmente, os produtores rurais não se assumem como empresários ao administrarem seus negócios e preferem se definir como agricultores. Com isso, o setor agropecuário não se fortalece e se mostra sem representatividade política. O referido autor comenta, ainda, que as limitações dos empresários rurais, sob o ponto de vista das expectativas modernas, são resultantes da falta de visão estratégica, despreparo para o relacionamento interpessoal, falta de audácia para a transformação de idéias em resultados, processo decisório lento, centralização e autoconhecimento.

Tais diferenças implicam em mudanças organizacionais nas propriedades do meio rural que queiram investir no turismo. Em função disso, o ambiente dessas propriedades tem se dinamizado buscando formas gerenciais que garantam sua inserção no mercado competitivo com a nova atividade. A habilidade das organizações em saber ler as situações, adotar uma estratégia adequada e sustentá-la é que pode garantir seu sucesso. Os produtores têm em suas mãos uma nova oportunidade de renda, de desenvolvimento, de resgate de sua dignidade profissional e do valor do meio rural. No entanto, os mesmos têm pela frente um grande desafio gerencial. Gerencialmente, sua performance deverá ser mais cautelosa e profissional, tanto pelas características do setor de turismo, quanto pelas características do produto e de sua produção, que são bem diferentes da costumeira no meio rural e demandam uma outra forma gestão. 
Gianese e Correa (1994), chamam a atenção sobre a forma de gerenciar serviços, dadas suas características. As áreas funcionais de marketing e recursos humanos são essenciais para sucesso do negócio. Alguns aspectos dessas duas áreas devem ser mais trabalhados, portanto, para que a sua gestão resulte na superação das expectativas dos clientes e assim alcance a competitividade. No caso da área de marketing, esses aspectos são as necessidades e expectativas dos clientes, os fatores que influenciam os seus comportamentos e sua avaliação sobre o serviço prestado. No caso da área de recursos humanos é a satisfação dos funcionários, e em muitos casos esses funcionários, são os próprios membros das famílias gestoras do negócio, que são os responsáveis pela qualidade dos serviços prestados. Além de suas características, o termo "serviço" abrange uma variedade de indústrias que desempenham várias funções para os consumidores.

Entramos em outro ponto de discussão e foco do trabalho, que é a diferenciação das submodalidades do turismo no espaço rural. Bravo (2003), cita "turismo rural como o conjunto de atividades turísticas praticadas no meio rural, comprometido com a produção agropecuária, agregando valor a produtos e serviços, resgatando e promovendo o patrimônio cultural e natural da comunidade”. Eis aí o marco conceitual resultante das Oficinas Nacionais realizadas na Embratur, em Brasília, nos meses de julho e novembro de 1998, ocasião em que estiveram reunidos, para esse fim, os mais representativos especialistas, a convite daquele Instituto. Devemos lembrar que, com a criação do Ministério do Turismo na gestão do atual do governo, essa terminologia deve ser alterada.

Em artigo publicado em uma revista eletrônica, Renato Bravo, ex-presidente da ABRATURR, verificou que além de excelente negócio, conciliar a produção familiar agropastoril ou extrativista com a atividade turística representaria, em si, o diferencial básico de autenticidade proposto no conceito adotado. Na plena contramão do êxodo rural, seus alicerces repousariam em quatro pilares fundamentais. Assim, teria sempre que se mostrar economicamente viável, ecologicamente equilibrado, socialmente justo e verdadeiramente rural. 
Tanto quanto possível, desviar-se-ia de estrangeirismos na veiculação dos produtos, valorizando o idioma e o sentimento de ruralidade. É certo que dominar línguas pressupõe obrigação de quem lida com turismo, mas sem deixar jamais de ressaltar o alcance da nossa unidade lingüística e a diversificação da cultura rural.

Para sua certificação o turismo rural brasileiro contemplaria o envolvimento com o afazer rurícola, com a agregação de valor a produtos e serviços da gente do lugar, seus costumes e tradições, guardada a permanente preocupação em preservar os valores mais genuínos da comunidade.

Turismo no espaço rural é uma modalidade de turismo que pode ser entendida como sendo toda maneira turística de visitar e conhecer o ambiente rural, enquanto se resgata e valoriza a cultura regional. Ele é capaz de integrar-se às práticas produtivas cotidianas da propriedade rural, permitindo o fortalecimento das atividades agropecuárias que são, ao mesmo tempo, atrações turísticas e fontes de renda. (Embratur, 1994).

Turismo no espaço rural, segundo Cavaco (2001), é um turismo de espaços naturais e, sobretudo, de espaços humanizados, ativos ou apenas contemplativos, que assegura um regresso ao passado pela cultura.

Existem diversas submodalidades que constituem o turismo no espaço rural na literatura. Segundo Roque (2001), estas variedades podem ser classificadas baseadas em valores com diversas motivações, oportunidades, necessidades e também elementos que compõem a oferta. Em outras submodalidades, segundo o produto turístico ofertado na propriedade rural, está o hotel-fazenda, fazenda-hotel, pousada-rural, colônias de férias rurais, entre outros, além do Agroturismo que podem interagir entre si, complementarem-se ou serem identificados isoladamente, dependendo da realidade local. Em outras palavras, a maioria das atividades do turismo no espaço rural não se verifica a interação do turista com o processo de produção, como observado no Agroturismo. 
Durante a revisão bibliográfica realizada, o autor que melhor apresentou a diferença entre o Agroturismo das demais submodalidades do turismo no espaço rural foi Rodrigues (2000), que defende que para uma atividade ser categorizada como turismo rural, tem que haver interação cultural, social e econômica no espaço rural. Cultural e social quando há contatos entre turistas e moradores do local, econômica quando há trocas de produtos ou valores entre o estabelecimento rural, o turista e a comunidade local.

\title{
Capítulo III. Agroturismo: em busca de uma definição
}

Uma definição bastante detalhada sobre o conceito de agroturismo é apresentada por Silva et al. (1998 apud ALMEIDA e RIEDL, 2000, p.148):

\begin{abstract}
"Atividades internas à propriedade, que geram ocupações complementares às atividades agrícolas, as quais continuam a fazer parte do cotidiano da propriedade, em menor ou maior intensidade, devem ser entendidas como parte de um processo de agregação de serviços aos produtos agrícolas e bens não materiais existentes nas propriedades rurais (paisagem, ar puro, etc.), a partir do 'tempo livre' das famílias agrícolas, com eventuais contratações de mão-de-obra externa.”
\end{abstract}

Segundo Desplanques (1973) o agroturismo “nasceu na Itália, em meados da década de 60 e era vista como uma alternativa de revitalização da economia rural, que na época sofria uma crise financeira e provocava o desestímulo de agricultores. Era também uma maneira de reverter o quadro de migração da população rural para s áreas urbanas, que somente entre as décadas de 50 e 70 somava mais de 5 milhões de italianos."

Viu-se então uma oportunidade de estimular a geração de receitas no meio rural e ainda promover o contato dos turistas com o dia-a-dia nas propriedades agrícolas, inclusive por meio de auxílio dos turistas nas diversas atividades cotidianas. 
De acordo com uma lei italiana que disciplina o Agroturismo, (G.U.R.I. 16-12-1985, n. 295), consideram-se agroturísticas "exclusivamente as atividades de recepção e hospedagem, exercidas por empreendedores agrícolas, individuais ou associados, e também suas famílias, através da utilização de sua própria fazenda, em relação de conexão e complementaridade à atividade de cultivo da propriedade, silvicultura, criação de animais, que devem permanecer a atividade principal. São consideradas atividades agroturísticas:

- Dar hospedagem, mesmo em espaços abertos destinados a campings;

- Servir alimentação e bebida em ambiente adequado, dentro da propriedade, prevalecendo aqueles produzidos com produtos próprios, inclusive as bebidas alcoólicas;

- Organizar atividades recreativas ou culturais nos ambientes pertencentes à propriedade.

Segundo Setúbal (1997), o agroturismo começou a ser explorado no Brasil, no final da década de 80, no Espírito Santo, com o produtor Leandro Carnielli. Com o resultado de suas atividades, várias outras propriedades agrícolas da região passaram a dedicar-se também a esta atividade e mais tarde, o governo do Espírito Santo criou o "Programa do Agroturismo", inicialmente implementado nos municípios de Afonso Cláudio, Castelo, Conceição do Castelo, Domingos Martins, Marechal Floriano, Vargem Alta, Viana e Venda Nova do Imigrante. Para fins deste trabalho, a afirmação acima é aceita como verdadeira, dada a atualidade das discussões, que pode vir a mudar em futuro próximo.

A idéia era gerar possibilidades para que as famílias de proprietários e trabalhadores das unidades rurais aprendessem a utilizar a produção das fazendas, as paisagens serranas, a cultura local, a hospitalidade do povo interiorano e a diversificada culinária regional como atrativos turísticos dos núcleos de agricultores. Atualmente acredita-se que aproximadamente duas centenas de propriedades já estejam envolvidas com a prática do agroturismo, pois o último levantamento, de 1995, não foi atualizado pelos gestores de Programa. Mais adiante aprofundaremos nos casos de experiências com a implantação do Agroturismo e o incentivo governamental. 


\section{III.I. O Agroturismo Técnico}

Atividades típicas do agroturismo são a venda direta dos produtos caseiros como doces, laticínios e embutidos, a comercialização dos produtos de artesanato, da pesca, bem como a hospedagem e o lazer, e dentre outras tantas podemos destacar a possibilidade de organização da visitação nas instalações e áreas de produção, sendo que esta linha apresenta intensa demanda de estudos mais aprofundados envolvendo o desenvolvimento de técnicas para a difusão tecnológica que propiciem agregação de valor aos produtos da propriedade rural.

O turismo de visitação não é novidade no meio rural, técnicos, produtores, estudantes utilizam estas visitas como forma de aprimoramento de conhecimentos em determinado assunto, produtores de sucesso recebem pessoas o ano inteiro e nunca foram remunerados pelos serviços, apenas recebem agradecimentos e a satisfação pela troca de experiências ou pela ajuda ao próximo, no entanto só agora, com o agroturismo é que essa "atividade de extensão rural" passa a ser mais trabalhada no sentido de uma organização metodológica buscando focar o visitante como turista e consequentemente como cliente dos serviços prestados pelo produtor rural que o recebe.

A propriedade que adota o agroturismo técnico é caracterizada pela fidelidade com os princípios fundamentais da sustentabilidade de um sistema de produção agrícola, realçando os métodos e propósitos que buscam a perenidade produtiva dos solos, onde a teoria e a prática de manejo ambiental é visualizada, convencendo o turista que ali se pratica a melhoria contínua nas propriedades físicas, químicas e biológicas do solo. Com relação à água o turista deve constatar que a sua utilização está alicerçada em técnicas que priorizam a racionalidade no consumo, bem como no tratamento para uso humano e dos animais, no tratamento de efluentes como esgotos e águas residuais provindas de residências, criatórios ou agroindústrias. Destacar a biodiversidade local é fundamental, disponibilizando para o turista a prazerosa atividade de contemplar inúmeras espécies vegetais recebendo informações técnicas relacionadas com suas utilidades ou curiosidades botânicas peculiares a cada espécie; o mundo vegetal guarda inúmeros atrativos turísticos, e o mesmo pode-se dizer para os animais, que fascinam os humanos em qualquer condição, sejam répteis, peixes, insetos, aves, crustáceos, 
mamíferos entre milhares de exemplares, que podem ser apreciados pelo visitante quando protegidos por fragmentos florestais ou matas ciliares, da mesma forma que os animais domésticos quando criados racionalmente constituem um tipo de atrativo onde um dos maiores objetivos são relatos de sucesso profissional com a exploração comercial, ou seja, agricultor ganhando dinheiro é verdadeiramente um constante atrativo no meio rural.

Alguns pontos, apesar de lógicos, são fundamentais de serem lembrados pelo agricultor interessado em praticar o agroturismo com sucesso: ações práticas de higiene pessoal demonstrando a todo momento saúde e disposição, além da higiene e limpeza de instalações, móveis e utensílios contribuem para obtenção de um selo de inspeção municipal, estadual ou federal que pelo menos oficializa a garantia de qualidade dos serviços prestados; outro ponto importante é a clareza nas ações relacionadas com a segurança no trabalho e do pessoal visitante, obras que facilitam o acesso de deficientes físicos, mentais, obesos e pessoal da terceira idade agregam valores inestimáveis de qualidade no atendimento e respeito à cidadania.

O tradicional cafezinho, normalmente oferecido, pode ser permeado por histórias, “causos”, e lembranças do passado que alegram as pessoas e trazem a tona um saudosismo extremamente salutar para os visitantes.

O agroturismo técnico é também caracterizado por ser regional abrangendo principalmente assuntos ligados aos diferentes sistemas de produção utilizados para a exploração de um determinado produto agrícola, normalmente grupos de proprietários se associam, viabilizando o chamado "circuito para visitação técnica" onde os participantes disponibilizam suas propriedades e áreas produtivas para que junto com os técnicos especializados desenvolvam o roteiro de visitação destacando como atrativos turísticos os elementos marcantes do sistema de produção bem como a tecnologia empregada; o próprio testemunho do produtor e os esclarecimentos técnicos por monitores capacitados são considerados como um forte agregador no interesse dos visitantes. 
Depois de estruturado o circuito, e consolidada a parceria entre os agricultores e técnicos, os serviços são oferecidos à comunidade disponibilizando as atividades para visitação de faculdades, escolas técnicas, escolas do primeiro e segundo grau, empresas, grupos de produtores e turistas de um modo geral.

O agroturismo técnico propicia também trocas de experiência entre os próprios participantes fortalecendo as relações de amizade, companheirismo, organização comunitária e principalmente o desenvolvimento local desencadeando uma imensa cadeia de negócios criando oportunidade de fixação do homem no campo.

\section{Capítulo IV. O Potencial do Agroturismo no Brasil}

A Associação Brasileira de Turismo Rural - ABRATURR -, possui oficialmente em seu cadastro 5 mil propriedades que exploram o turismo no espaço rural. Mas o número de propriedades que exploram a atividade, segundo a própria ABRATURR pode passar de 10 mil e tem crescido a uma média de $18 \%$ ao ano. Em 2001, o turismo no espaço rural movimentou uma cifra da ordem R 1,6 bilhão e as propriedades receberam cerca de 10 milhões de visitantes. O setor, de acordo com os números da ABRATURR, gera 100 mil empregos diretos e outros 500 mil indiretos. Os empreendimentos estão direcionados para diversas categorias do turismo com acampamento rural, “day camp”, fazenda de pesca com hospedagem, fazenda com pesque-pague, fazenda turismo (pousada rural), hotel ecológico (lodge), hotel-fazenda "spa rural” e turismo eqüestre. Vale lembrar que fazenda turismo/pousada rural e hotelfazenda não devem ser incluídos na categoria de agroturismo, considerando que são apenas empreendimentos hoteleiros.

- Região Sul: possui excelente potencial nos 3 estados da região.

Santa Catarina: estado pioneiro no turismo no espaço rural, possui cerca de 1.200 leitos em propriedades rurais, distribuídos em 80\% no Planalto Serrano, 5\% no Vale do Itajaí e os $15 \%$ restantes no restante do estado. 
Rio Grande do Sul: dos 500 mil estabelecimentos rurais do estado, (Secretaria de Agricultura, 1997, 199 são propriedades turísticas rurais cadastradas em 37 municípios. Paraná: há cerca de 20 propriedades desenvolvendo o Turismo no Espaço Rural.

- Região Sudeste: bom potencial

São Paulo: ínício em 1996, através do fomento oferecido pelo SEBRAE/SP, no programa "Volta ao Campo" (conscientização, motivação, diagnósticos de viabilidade). Em um ano, 1.000 produtores assistiram a palestras, 80 diagnósticos forma desenvolvidos, 10 dos quais estão em operação.

Minas Gerais: consolidada há cerca de 3 anos, conta com uma associação (AMETUR), com 16 associados. O número de leitos que atendem ao Turismo no Espaço Rural é cerca de 750.

Rio de Janeiro: a TURISRIO está (em 1999) começando a estimular o desenvolvimento da atividade.

Espírito Santo: é a região que mais desenvolve o Agroturismo, a maior parte dos estabelecimentos não oferece pernoite. O SEBRAE/ES é muito ativo no incentivo ao desenvolvimento da atividade e conta com o apoio do Governo Estadual e das Prefeituras.

- Região Nordeste: alguns estados, como Bahia e Pernambuco, possuem grande potencial.

Bahia: algumas iniciativas de particulares na periferia de Salvador. A partir de 2000, o SEBRAE, em parceria com o Governo do Estado, começou a promover ações de conscientização e alguns projetos estão sendo implantados (Costa do Cacau, sul da Bahia). Importante citar que este projeto para preservação florestal nessa região vem da necessidade de sombreamento nas plantações de cacau.

Pernambuco: há 3 anos, tiveram início algumas iniciativas particulares na região de Garanhuns.

\section{- Região Norte:}

Pará: em um ilha do rio Xingu distante 100 quilômetros do município de Altamira, a Cooperativa Mista de Produtores e Extrativistas - Campealta - inaugurou o Hotel 
Tataquara. Recursos e financiamentos foram conseguidos junto às ONGs internacionais. A Cooperativa é formada por 1.200 índios de nove tribos.

As instalações são ecologicamente corretas, abastecidas por energia solar e com sistemas de tratamento de efluentes. Os lucros da exploração turística serão utilizados na fiscalização das terras indígenas, contribuindo assim para a preservação da floresta.

- Região Centro-Oeste: excelente potencial

Mato Grosso do Sul: início das atividades em 1995, com o apoio do SEBRAE/MS, em parceria com o governo do Estado. Oferece cerca de 400 leitos distribuídos em 45 propriedades. Cada pousada não recebe mais que 40 hóspedes por vez, que acompanham o transporte do gado para regiões altas e a marcação de bezerros.

Distrito Federal: Atualmente são mais de 90 empreendimentos de turismo no espaço rural em funcionamento na área Administrativa do Distrito Federal, e por isso merece uma atenção especial no capítulo a seguir.

\section{Capítulo V. Experiências Bem Sucedidas do Agroturismo}

A escolha destas duas unidades federativas se deve apenas por se tratar de duas das regiões brasileiras onde o agroturismo vem sendo mais desenvolvido com o apoio de instituições governamentais que veremos em capítulo oportuno.

\section{V.I. Venda Nova do Imigrante - ES}

O interesse do governo do estado do Espírito Santo em implementar programas de fomento ao turismo nas áreas serranas do estado já era considerado estratégico, pelo fato da sua abrangência socioespacial, que envolvia um setor do espaço capixaba que experimentava 
períodos difíceis com as constantes crises econômicas e políticas do estado, em razão da falta de recursos para investimentos e financiamentos em vários setores produtivos.

Como já exposto anteriormente, o turismo no espaço rural capixaba, iniciou-se no final da década de 80, com o produtor Leandro Carnielli, na região turística conhecida como “Triângulo das Montanhas”. Carnielli acreditava que alguns problemas do campo, como êxodo rural, a perda do excedente da produção, a desmotivação dos produtores mais jovens, bem como uma série de outros incômodos, poderiam ser resolvidos, pelos menos em parte, pelo associativismo. Partindo dessa crença, iniciou a atividade de visitação à propriedade “Fazenda Providência”, no município de Venda Nova do Imigrante (cem quilômetros da capital Vitória), motivando outros proprietários a tomar a mesma iniciativa.

O governo do estado do Espírito Santo, por intermédio da suas secretarias de desenvolvimento econômico e de agricultura, em parceria do SEBRAE/ES, decidiu investir firmemente no segmento do turismo no espaço rural, criando assim o "Programa do Agroturismo”, estendendo-se por outros municípios. Formou-se então, a Região Serrana Central do Espírito Santo.

O foco do Programa é possibilitar o uso dos atrativos turísticos nos núcleos agrícolas como por exemplo as paisagens serranas, a culinária, a hospitalidade interiorana, a produção das fazendas, como nova ferramenta das famílias de proprietários e trabalhadores das unidades rurais

O processo de implementação efetiva do Programa incrementou-se a partir da criação do Agrotur - Centro Regional de Desenvolvimento do Agroturismo, criado em 05/03/1993, como associação civil, sem fins lucrativos, que tinha como principal função congregar os produtores rurais dos municípios envolvidos, bem como instituições e órgãos de interesse do/no setor, para juntos buscarem as melhores formas de operacionalizar essa tipologia de turismo. Sua sede foi instalada no município de Venda Nova do Imigrante e atualmente não serve mais de referência para os novos produtores interessados em aderir ao programa, pois dirigiu sua atenção apenas para o município que o sedia. Dessa forma, desvirtuou-se de seus objetivos 
iniciais, permitindo que qualquer interessado possa passar a atuar no setor agroturístico, fato que resultou da descaracterização dos objetivos iniciais do Programa.

Diante dessa situação, em cada município o proprietário tem procurado organizar associações locais para conduzir de forma particularizada os objetivos de seus integrantes. Bom exemplo desse movimento foi a criação em fevereiro de 1998, da Acetur - Associação Afonso Claudense de Turismo, cujo objetivo era justamente suprir a lacuna deixada pelo Agrotur.

Outra função que era atribuída ao Agrotur era pôr em prática o conjunto de preposições do Programa, que até o momento conta com os esforços da EMATER e sobretudo do SEBRAE, que na realidade é quem vem operando uma série de intervenções para promover essa atividade, substituindo em parte as atribuições do Centro Regional de Desenvolvimento do Agroturismo.

O agroturismo demonstra-se como uma das atividades com maior poder de geração de renda na região onde está sendo explorado, no Espírito Santo, com média de crescimento de renda de 30\%. Apesar disso a atividade não foi capaz, ainda, de aumentar a oferta de emprego para terceiros, visto que em sua a maioria, as propriedades agroturísticas são tocadas por famílias de agricultores.

\section{V.II. O Distrito Federal}

Quando o SEBRAE/DF iniciou os trabalhos com o turismo no espaço rural, em 1996, havia duas referências: a experiência de Venda Nova do Imigrante e a experiência de Lages, em Santa Catarina, considerada segundo Zimmermman (2000) como “a Capital Nacional do Turismo Rural”. 
Depois de obter as informações de ambas as regiões, observou-se que o estado do Espírito Santo era o que mais se assemelhava à realidade do Distrito Federal, pois são pequenas propriedades com uma grande diversificação de atividades agropecuárias e agroindustriais disponibilizadas para os turistas.

Já em 1996, a iniciativa privada começava a desenvolver nos arredores de Brasília a atividade, que tinha a denominação de "Restaurantes Rurais”. Mas somente nos biênio 98/99, surgiram as parcerias do SEBRAE/DF com a EMBRATUR, a Secretaria de Turismo e Lazer do Distrito Federal (SETUR/DF), o Sindicato Rural do Distrito Federal (SRDF) e a Secretaria de Agricultura do Distrito Federal (SA/DF).

Para conhecer melhor a experiência do Espírito Santo, o SEBRAE/DF organizou, com os empreendedores interessados um seminário em Brasília e convidou para palestrantes o Sr. Leonardo Carnielli, líder daquele movimento nas regiões serranas do estado do Espírito Santo e a Sra. Vera Perin, do SEBRAE/ES. Os resultados do encontro foram positivos: participação intensa e proveitoso repasse do modelo de implantação do projeto naquela região.

Em face da escolha desse modelo e do interesse dos empresários, foi planejada e realizada a primeira caravana ao Espírito Santo, com aproximadamente 30 empreendedores, a fim de observar in loco o funcionamento do projeto. A visita a vários empreendimentos da região foi fator determinante para alguns participantes da caravana tomarem a decisão de implantar um empreendimento com características semelhantes no Distrito Federal.

A implantação do Projeto de Turismo Rural no Distrito Federal tem contribuído para o aumento de negócios em agroturismo, contando com o apoio governamental e entidades envolvidas com o meio agrícola. O melhor de tudo isso é observar que o proprietário busca esses profissionais especializados já preocupado em atender as novas necessidades mercadológicas que irá enfrentar, como planejamento e gestão empresarial do negócio, noções de hospitalidade, hospedagem e atendimento ao turista. 


\section{Capítulo VI. As Entidades Governamentais e suas Ações}

Os órgãos apresentados a seguir não são os únicos a apoiarem a atividade do turismo no espaço rural no Brasil. Há diversas outras entidades ligadas ao fomento do setor, mas as relacionadas neste trabalho foram as entidades que mais apresentaram resultados, inclusive documentados, nos últimos 10 anos.

\section{VI.I. O SEBRAE}

Podemos notar a presença do SEBRAE - Serviço Brasileiro de Apoio às Micro e Pequenas Empresa - em todas as regiões do Brasil, formando parcerias com Associações, Cooperativas, Sindicatos Rurais, Consultorias, os governos Municipais e Estaduais e também ONGs nacionais e internacionais.

O Programa SEBRAE de Turismo propõe ações sistematizadas de desenvolvimento auto-sustentável para os municípios brasileiros, onde preferencialmente já tenha sido implantado o Programa de Emprego e Renda (PRODER) ou o Programa Nacional de Municipalização do Turismo (PNMT), sendo que este último não está acontecendo desde o início da gestão do governo Luiz Inácio Lula da Silva.

As primeiras demandas relativas ao segmento turismo no espaço rural que começaram a chegar ao setor de atendimento do SEBRAE eram envolvidas pelas preocupações dos produtores rurais que buscavam alternativas economicamente viáveis para a manutenção de suas propriedades. Embora algumas iniciativas incipientes viessem marcando presença no mercado, ainda não haveria densidade para estabelecer o que hoje se denomina segmento de turismo no espaço rural.

Para atuar no Projeto de Turismo no Espaço Rural, inicialmente e erroneamente denominado como Agroturismo, as equipes dos setores de turismo e agroindústria dos SEBRAE começaram a visitar algumas propriedades para analisar o potencial existente - 
belezas naturais e infra-estrutura instalada -, que poderia ser útil e motivador para o turista, como conhecimento (casa antiga, museu, agroindústria, casa de farinha, engenho), ou como receptivo, hospedaria, restaurante e outros.

Esse olhar diferenciado do olhar técnico que só vislumbra a produção deu outra dimensão àquelas visitas: a avaliação mais detalhada possibilitou à equipe aperfeiçoar o nível de observação e de conhecimento.

O registro dessas observações transformou-se no Inventário do Patrimônio Rural, no qual se apresentava a propriedade mapeada em todos os aspectos: localização, acesso, infraestrutura básica, atrativos naturais, históricos e culturais, produção agrícola e envolvimento comunitário.

Essa fase, compartilhada com os Sindicatos Rurais e a EMATER - Empresa de Assistência Técnica e Extensão Rural -, tem como fatores determinantes a integração dos membros da equipe e a constante troca de informações e conhecimento.

Outra experiência relevante é a implementação do diagnóstico de avaliação para a implantação de um empreendimento de turismo no espaço rural. Esse instrumento, elaborado inicialmente como um protótipo para assegurar ao empreendedor a viabilidade da aplicação dos recursos nessa nova atividade, é hoje um documento completo e importante para nortear o nível de investimento e o de retorno em determinado período de tempo, o que traz ganhos relevantes para a equipe e para os empreendedores, pelas informações valiosas e pela criação de sinergia no processo.

Paralelamente aos estudos de viabilidade e esforços para gestão de competências, o SEBRAE investe na editoração de publicações de apoio ao desenvolvimento do segmento do Turismo no Espaço Rural. De guias regionais a folhetos de divulgação específica, de manuais mercadológicos a publicações técnicas e estudos sobre ocupação de espaços na Internet, um amplo material foi editado de forma a registrar o que já se pode chamar de "uma cultura do turismo no espaço rural e ecológico no Brasil”. 


\section{VI.II. O SENAR}

Uma outra entidade governamental identificada no envolvimento com o Agroturismo é o Serviço Nacional de Aprendizagem Rural - SENAR - que foi criado em 23 de dezembro de 1991, e que previa sua criação nos moldes do SENAI e SENAC. É uma Instituição de direito privado, mantida pela classe patronal rural, vinculada à Confederação da Agricultura e Pecuária do Brasil - CNA e dirigida por um Conselho Deliberativo.

O SENAR baseia suas ações em princípios e diretrizes estabelecidas pela Organização Internacional do Trabalho - OIT, nas políticas do Centro Interamericano de Investigação e Documentação sobre Formação Profissional- CINTERFOR, formuladas durante reuniões de comissões técnicas, nas políticas dos Ministérios do Trabalho e da Agricultura e nas diretrizes emanadas da CNA e suas Federações vinculadas.

O objetivo do SENAR é organizar, administrar e executar, em todo território nacional, a Formação Profissional Rural (FPR) e a Promoção Social(PS) de jovens e adultos, homens e mulheres que exerçam atividades no meio rural. As ações do SENAR são organizadas e desenvolvidas de forma sistematizada, seguindo um processo de planejamento, execução, acompanhamento, avaliação e controle. São ações educativas, que visam o desenvolvimento do Homem rural, como cidadão e como trabalhador, numa perspectiva de crescimento e bemestar social. Para isso, o SENAR conta com equipe técnica, multidisciplinar, responsável pela condução dos trabalhos e com equipe de instrutores, previamente preparados em uma metodologia de ensino ideal para repassar seus conhecimentos técnicos ao trabalhador e produtor rural.

"Formando e Promovendo o Homem do Campo". Este é o princípio metodológico do SENAR, que enfatiza a necessidade de atuação através de um processo de ensino onde a atividade prática se torna de vital importância à aprendizagem. Para isto, os locais escolhidos para a execução das ações sempre estão relacionados a uma situação real de trabalho, onde os treinandos participam ativamente das ações e assimilam com maior rapidez o que lhes é repassado, já que a aprendizagem é adquirida daquilo que as pessoas vêem, escutam, discutem 
e, principalmente, praticam. O mais recente curso oferecido ao trabalhador rural é o de prestação de serviços na área do turismo no espaço rural.

\section{VI.III. O Ministério do Turismo}

A partir do entendimento de que o turismo se constitui em um importante setor para alavancar o crescimento econômico, essa atividade vem crescentemente sendo considerada pela sociedade brasileira capaz de traduzir nossa imensa riqueza natural, étnica e cultural, bem como nossa capacidade empreendedora em efetivo instrumento de geração de emprego e renda, contribuindo para melhoria da qualidade de vida e inclusão social. (Embratur)

O papel do turismo como atividade econômica relevante, capaz de oferecer contribuição significativa para solução de problemas tão presentes como a criação de empregos e a geração de divisas, não é, entretanto, percebido claramente em sua verdadeira dimensão. Cabe registrar que, entre 1994 e 2000, segundo a Embratur, o número de estabelecimentos relacionados ao turismo cresceu de 83.436 para 150.227. No mesmo período, os empregos gerados evoluíram de 3.322.550 para 5.811.220. O quadro a seguir mostra a presença do turismo na balança comercial, assumindo a quarta posição como gerador de receitas.

O turismo no Brasil vem crescendo consistentemente. No entanto, o cenário otimista que se desenhava para o ano de 2002, com expectativa do aumento do fluxo de turistas estrangeiros, foi frustrado diante dos acontecimentos de 11 de setembro de 2001, que desencadearam uma crise mundial sem precedentes nas companhias aéreas e operadoras de viagem. Esse quadro foi agravado pela crise econômica da Argentina, importante pólo emissivo para o Brasil. No tocante ao turismo interno, as dificuldades da economia brasileira impediram um crescimento mais expressivo das viagens domésticas, embora estas tenham evoluído em relação ao ano anterior, pois a alta do dólar fez que muitos brasileiros trocassem destinos no exterior por destinos no Brasil. 
Com o objetivo de consolidar e ampliar o setor como atividade econômica geradora de emprego, trabalho e melhoria da distribuição de renda, ratifica-se a necessidade de realizar um esforço de investimento permanente em infra-estrutura básica e turística, qualificação de recursos humanos e principalmente nas ações de promoção e marketing.

As questões conjunturais verificadas não podem servir de empecilhos para a consolidação do setor. Para tanto, devemos romper com as limitações estruturais existentes, ressaltando-se, dentre elas, a pouca oferta de produtos diversificados, e buscar a solução dos problemas na construção de parcerias e articulações coletivas entre o setor público e a sociedade organizada.

Diante desses desafios e acreditando que o turismo se constitui em um importante vetor de desenvolvimento econômico e social, o Governo Federal, em seu primeiro ato, criou o Ministério do Turismo, demonstrando sua convicção na capacidade do setor de contribuir para um Brasil melhor.

O Ministério do Turismo tem como metas prioritárias de sua gestão:

- Atingir até 2006 o total de 9 milhões de turistas estrangeiros por ano, gerando divisas na ordem de US\$ 8 bilhões; e

- Aumentar de 41 milhões para 60 milhões os desembarques anuais nos vôos domésticos e criar condições para gerar 1,2 milhão de novos empregos no turismo ao final do período.

A Empresa Brasileira de Turismo - EMBRATUR - será a responsável pela promoção do turismo brasileiro no exterior. Por tratar do marketing nacional, não entraremos em detalhes na estruturação e missão da EMBRATUR neste trabalho. 


\section{VI.IV. O Ministério da Agricultura e do Abastecimento}

Com o objetivo de ativar linhas de crédito que possibilite ampliar a renda familiar, para desenvolver a propriedade rural, fortalecer a agricultura familiar e abrir novas oportunidades de emprego e de renda no meio rural, o Ministério da Agricultura e do Abastecimento criou o Programa de investimentos para agregação de renda à atividade rural - PRONAF-AGREGAR.

Apoiar financeiramente mediante abertura de crédito a investimentos em infra-estrutura, que visem ao beneficiamento, ao processamento e à comercialização de produção agropecuária e/ou de produtos artesanais desenvolvidas por famílias rurais, inclusive para exploração do turismo e lazer rural é a principal finalidade do Programa. Pode ainda implantar pequenas e médias agroindústrias, isoladas ou em forma de rede, e unidades centrais de apoio gerencial, nos casos de agroindústrias em rede, para a prestação de serviços de controle de qualidade do processamento, de marketing, de aquisição, de distribuição e de comercialização da produção.

\section{Considerações Finais}

As pesquisas acadêmicas no Turismo têm crescido de forma contínua nos últimos anos. Esse crescimento se deve, entre outros fatores, ao aumento de parcerias das Instituições de ensino com setores públicos e privados. Como conseqüências dessa mútua colaboração, ocorreu uma maior profissionalização no setor, objetivando não só a capacitação dos profissionais da área, mas principalmente a busca de sua sustentabilidade.

Considerando a complexidade gerencial do setor de turismo e as características do setor rural, como a cultura, o tipo de produto, o tradicionalismo e informalidade gerencial, dentre outras, fica evidente a necessidade de uma reorganização das propriedades rurais que queiram atuar na área de turismo. 
O motivo que leva esse produtor rural a introduzir a atividade de turismo em sua propriedade, é o risco que o mesmo corre em ter que fechar as porteiras, pelo fato das atividades tradicionais de produção não estarem rentáveis ou lucrativas a ponto de cobrir todos os custos. Diante dessa situação o produtor percebe que o turismo pode ser uma alternativa de renda que permite a superação de tal dificuldade. A partir daí, várias mudanças têm que ser realizadas na propriedade e várias dificuldades são enfrentadas pelo produtor, mas que segundo o mesmo, gera resultados positivos.

Com a atividade de turismo, algumas mudanças organizacionais internas ocorreram na propriedade rural. Essas mudanças resultaram de uma nova forma de comportamento coletivo na adoção de procedimentos gerenciais adequados aos serviços de turismo como o conhecimento dos desejos dos clientes, objetivos e estratégias, a busca da eficiência global, a qualidade coordenada interna e externa como competência, pertinência dos esquemas de decisão, comunicação clara.

Todas as mudanças, com certeza, foram e são enfrentadas com muito esforço e dificuldades. As dificuldades enfrentadas foram e ainda são: a escassez de recursos monetários para investir em capacitação, adequações físicas, divulgação do potencial e produto turístico, além da impossibilidade de realizar empréstimos em bancos por causa dos juros altos, a falta de visão em trabalhar com prestação de serviços e a sua cultura tradicional de "senhor”. Em geral, os produtores rurais, relutam em abandonar essa postura tradicional de "senhor" para ser o "servidor”. Os mesmos têm ciúmes do seu patrimônio, não sabem como cobrar e se sentem constrangidos em receber o dinheiro.

Abrir as porteiras para estranhos usufruir daquilo que mais os orgulham é a maior dificuldade enfrentada e que vem a interferir na decisão de atuarem na prestação dos serviços de turismo. Atualmente essas dificuldades estão vencidas, com exceção da escassez de recursos monetários e da falta de crença dos agentes de turismo como agências e operadoras e outros em relação a prestação de serviços de turismo no espaço rural.

Ao transpor todo o processo decisório de implantação de atividades turísticas em sua propriedade, o produtor rural deverá ainda definir o tipo de empreendimento que irá explorar. 
É aí que ele se defronta com várias tipologias de turismo no espaço rural, que acabam por confundi-lo. O trabalho identificou algumas dessas tipologias, mas enfatizou apenas o Agroturismo, como sendo a única atividade do turismo no espaço rural que se observa a interação do turista com o processo de produção do meio rural. Ainda há muitos autores que definem o Turismo no Espaço Rural e o Agroturismo como sendo a mesma atividade. Mas é esperado que com a criação do Ministério do Turismo as novas Oficinas Nacionais organizadas pela Embratur possam conceituar de forma correta os segmentos do turismo no espaço rural.

A participação cada vez mais atuante de entidades governamentais e a utilização de estudos acadêmicos, como exposto anteriormente, também tem contribuído para o desenvolvimento do Agroturismo nas regiões brasileiras. Em recente encontro organizado pelo Centro de Excelência em Turismo da Universidade de Brasília - CET/UnB, com a participação de outras faculdades locais, o SEBRAE, a Secretaria de Turismo do DF, entre outros foram diagnosticadas as atividades do turismo no espaço rural do Distrito Federal e apresentadas sugestões para os gestores da atividade a nível governamental e não governamental que podem ser facilmente aplicadas nas demais regiões do País. Como por exemplo o estabelecimento de políticas públicas voltadas ao desenvolvimento dessas mesmas atividades visto que 55\% dos empreendimentos apresentam sustentabilidade econômica, mesmo considerando todas as dificuldades enfrentadas pelos empreendedores. Incentivos ao treinamento e capacitação de empreendedores e empregados e o apoio à instalação de toda infra-estrutura necessária: transporte, estradas pavimentadas e bem sinalizadas para o acesso, comunicações, energia elétrica, saneamento básico, segurança e demais necessidades que devam ser observadas e consideradas quando do planejamento da atividade nas regiões.

Com a criação do Ministério do Turismo é aguardado os resultados do Plano Nacional do Turismo (2003-2007), que segundo as entidades que contribuíram para a elaboração do documento, entre elas a Associação Brasileira de Turismo Rural - ABRATURR, deve ser de importância vital para os negócios já estabelecidos como para os que venham a se estabelecer. 


\section{Referências Bibliográficas}

AGROTUR - Centro Regional de Desenvolvimento do Agroturismo. Estatuto do Agrotur. Venda Nova do Imigrante: Agrotur, A.D.

AIRES, M; RENTERO, N. Desvantagem para o leite brasileiro ameaçam o setor. Balde branco, São Paulo, v.26, n. 334, p. 18-21, ago. 1992.

BENI, Mário. C. Mesa redonda: gestão de turismo no Brasil. Revista de Administração, São Paulo, v. 33, n. 4, p. 5-25, out./dez., 1998.

BRAVO, Renato. Turismo Rural, esse desconhecido. Artigo publicado na revista eletrônica Estudos Turísticos.Com. Disponível em < http://www.estudosturisticos.com.br/renatobravo $>$ Acesso em 05 de nov. 2003.

CAVACO, Carminda. Turismo rural e desenvolvimento local. In: Rodrigues, B. A A. Turismo e geografia. São Paulo: Hucitec, 2001. p.94-121.

CENTRO DE EXCELÊNCIA EM TURISMO, NÚCLEO DE APOIO À COMPETITIVIDADE E SUSTENTABILIDADE DA AGRICULTURA, SERVIÇO BRASILEIRO DE APOIO ÀS MICRO E PEQUENAS EMPRESAS-DF. Diagnóstico das Atividades de Turismo Desenvolvidas no Espaço Rural do Distrito Federal e em Algumas Áreas do Entorno. Relatório Técnico. Brasília, 2003. 76p.

CORNER, D. M. R. Introdução ao turismo. São Paulo: Roca, 2001. 371 p.

DESPLANQUES, Henri. Une Nouvelle Utilisation de Léspace Rural en Italia: l’Agritourisme. Annales de Géographie, 82 (450): 151-64, mars-avril, 1973.

EMBRATUR - Instituto Brasileiro de Turismo. Manual do turismo rural. Brasília: Ministério da Indústria, do Comércio e do Turismo, 1994.

EMBRATUR. Disponível na Internet em < http://www.embratur.gov.br $>$ Acesso em 05 de nov. 2003.

ESTADO DO ESPÍRITO SANTO. - SEDES - Secretaria de Estado do Desenvolvimento Econômico. Agroturismo - região serrana central do estado do Espírito Santo: perfil de preposições. Vitória: SEDES/SEAG, 1992.

GAZETA MERCANTIL, 21de ago.2002. Disponível na Internet em < http://www.geomagna.com.br/news132.htm > Acesso em 23 de nov. 2003

GIANESE, I. G. N.; CORRÊA, H. L. Administração estratégica de serviços. São Paulo: Atlas, 1994. 233 p. 
HUBERMAN, Leo. História da Riqueza do Homem. Tradução de Waltensir Dutra. Rio de Janeiro: Zahar Editores. 9a edição, 1973.

LICKORISH, L. J. e JENKINS, C. L. Introdução ao Turismo. Rio de Janeiro: Campus. 2000

LUCENA, M.D.da S. Avaliação de desempenho. São Paulo: Atlas, 1992. 151p.

MENDONÇA, Maria C. A. Da propriedade agrícola ao turismo rural [on-line] Disponível na Internet em: < http://www.estudosturisticos.com.br > Acesso em 30 de out. 2003.

OLIVEIRA, Cássio G. S. Implantação do Turismo em Propriedades Rurais. São Paulo: Ed. SENAC, 2000.

RODRIGUES, Adyr B. Turismo eco-rural. Interfaces entre o ecoturismo e o turismo rural. In: ALMEIDA, Joaquim A.; FROEHLICH, José M. \& RIEDL, Mário. Turismo rural e desenvolvimento sustentável. Santa Maria: UFSM, 1998.

RODRIGUES, Adyr B. Turismo rural no Brasil - ensaio de uma tipologia. In: : ALMEIDA, J.A.; RIEDL, M (org.). Ecologia, lazer e desenvolvimento. São Paulo: Universidade Sagrado Coração, 2000.

SEBRAE. Disponível na Internet em: < http://www.sebrae.gov.br/projetosdeturismo $>$ Acesso em 02 de nov. 2003.

SEBRAE/ES - Serviço Brasileiro de Apoio à Micro e Pequena Empresa. Mapa do Agroturismo. Vitória, A.D. Material para divulgação.

SEBRAE/DF - Serviço Brasileiro de Apoio à Micro e Pequenas Empresas. Turismo Rural no Distrito Federal e Entorno. Brasília; Ed. SEBRAE, 2003.

SETÚBAL, Ana C. B. Agroturismo: Uma Forma de Turismo Rural. Anais do $1^{\circ}$ Encontro Nacional de Turismo com Base Local. São Paulo: DG-FFLCH/USP, $10-3$ de maio, 1997, p.166-8.

SILVA, José Graziano da; VILARINHO, Carlyle \& DALE, Paul J. Turismo em áreas rurais: suas possibilidades e limitações no Brasil. In: ALMEIDA, Joaquim A.; FROEHLICH, José M. \& RIEDL, Mário. Turismo rural e desenvolvimento sustentável. Santa Maria: UFSM, 1998.

SILVA, José Graziano. A Nova Dinâmica da Agricultura Brasileira. Campinas, SP.: UniCamp. IE, 1996.

TULIK, Olga. Do conceito às estratégias para o desenvolvimento do turismo rural”, in Rodrigues, Adyr. (org.).Turismo - desenvolvimento local. - São Paulo: Editora Hucitec. 1997, p.136-143.

WALKER, Jonh R. Introdução à Hospitalidade. Tradução de Elcio de Gusmão Verçosa Filho. Barueri, SP.: Mande; $2^{\mathrm{a}}$ ed., 2002. 
ZIMMERMANN, Adonis. Turismo rural: um modelo brasileiro. Florianópolis: Autor, 1996. 67p. 